Article

\title{
Ultrasound-Assisted Extraction of Bioactive Compounds and Antioxidant Capacity for the Valorization of Elaeocarpus serratus L. Leaves
}

\author{
Ying-Hsuan Chen and Chun-Yao Yang *D \\ Department of Food Science, Fu Jen Catholic University, No. 510, Zhongzheng Rd., Xinzhuang Dist., \\ New Taipei City 242062, Taiwan; J1280285jj@gmail.com \\ * Correspondence: 133810@mail.fju.edu.tw; Tel.: +886-2-29053624
}

Received: 10 September 2020; Accepted: 27 September 2020; Published: 29 September 2020

\begin{abstract}
Elaeocarpus serratus L. leaves contain significant polyphenols, flavonoids, and myricitrin with medicinal property, which are byproducts after harvest and can be recovered for potential food applications. In this study, the effective extraction method for bioactive compounds and myricitrin from Elaeocarpus serratus L. leaves was investigated by comparing ultrasound-assisted extraction (UAE) and shaking-assisted extraction (SAE) for total phenolic content (TPC), total flavonoid content (TFC), myricitrin, and antioxidant capacity (as ferric reducing antioxidant power, FRAP). A first-order kinetic model of extraction was also proposed to correlate the observed extraction rate coefficient and limiting concentration of myricitrin in various solvents. Using defatted leaves (DL) as the substrate at the UAE condition of $95 \%$ ethanol with $1 / 10(\mathrm{~g} / \mathrm{mL})$ of DL to solvent ratio under $40 \mathrm{kHz} / 300 \mathrm{~W}$ of ultrasound, $26.63 \%$ of yield of extract, and $199.75 \mathrm{mg}$-ferrous-sulfate-heptahydrate-equivalent/g-DL of FRAP were obtained. Further, the bioactive compounds extracted were $92.35 \mathrm{mg}$-gallic-acid-equivalent/g-DL of TPC, 53.14 mg-rutin-equivalent/g-DL of TFC, and $4.41 \mathrm{mg} / \mathrm{g}$-DL of myricitrin, which were 1.53, 1.44, and 1.4 folds using SAE at $120 \mathrm{rpm}$, respectively. This showed that UAE was more efficient than SAE in bioactive compounds recovery for valorization of Elaeocarpus serratus L. leaves.
\end{abstract}

Keywords: Elaeocarpus serratus L.; ultrasound-assisted extraction; myricitrin; bioactive compounds

\section{Introduction}

Elaeocarpus serratus L. are an evergreen plant native to Sri Lanka and India, and have been widely planted in subtropical and tropical Asian regions, tropical Australia [1,2], and central and southern Taiwan [3]. The fruit of Elaeocarpus serratus L. is rich in carbohydrates, protein, vitamins, and polyphenolic compounds, boding high nutrients beneficial to human health [2,4]. Moreover, it is locally prescribed for the treatment of diarrhea and dysentery [5]. The leaves of Elaeocarpus serratus L. contain a significant amount of polyphenols and flavonoids, including myricitrin with pharmacological properties, and can be used to treat rheumatism and as an antidote to poison [5].

Polyphenols and flavonoids have many biological activities and occur in plant materials. In Elaeocarpus serratus L. leaves, some flavonoids are significantly present, including myricitrin, mearnsitrin, and mearnsetin [6], among which myricitrin can play important role in human health. Myricitrin was reported to possess antioxidant activity with a stronger free radical scavenging activity than other flavonol rhamnosides or quercetin [7]. Myricitrin has a number of potential benefits, such as antioxidant, anti-inflammatory, anti-mutagenic, and anti-nociceptive activities. The bioavailability of myricitrin in food occurs in the hydrolysis to release its aglycone in the small intestine [8]. In animal models, myricitrin displayed an antipsychotic-like effects, antidepressant-like effect, and a significant hepatoprotective activity $[7,9,10]$. Therefore, the extract of Elaeocarpus serratus L. leaves can be 
considered an economic source of polyphenols, flavonoids, and myricitrin. Hence, an effective and sustainable method applied in the extraction of Elaeocarpus serratus L. leaves would be useful.

Ultrasounds are regarded as a non-thermal green technology and have been applied in various fields to enhance either chemical reactions or unit operations, including food processing. Specifically, the mechanisms involved in the extraction process using ultrasounds are due to the cavitation effect (i.e., fragmentation, destruction, erosion, capillary action, local shear stress, and sonoporation) [11]. Thus, the extraction of polyphenols, polysaccharides, and functional compounds solubilizing into the appropriate solvent can be facilitated [12-16].

Since Elaeocarpus serratus L. leaves are usually used as compost in situ or processing waste after a fruit harvest, further valorization of the leaves would be advantageous via antioxidant constituent extraction for potential use in food as a nutrient supplement. Thus, an efficient method that can process Elaeocarpus serratus L. leaves is needed. In this study, we investigated an extraction method for bioactive compounds from Elaeocarpus serratus L. leaves and evaluated the antioxidant capacity of the extract. The total phenolic compounds, flavonoids, myricitrin, and antioxidant capacity between shaking-assisted extraction (SAE) and ultrasound-assisted extraction (UAE) at different frequencies, as well as the solvent effect, were compared. Moreover, the kinetic model of extraction was proposed to correlate the extraction coefficient and limiting concentration of myricitrin extracted in the solvent to identify the rate of extraction using UAE for future development.

\section{Materials and Methods}

\subsection{Materials}

The leaves of Elaeocarpus serratus L. were collected in October 2018 from the Elaeocarpus serratus L. orchard $\left(23^{\circ} 29^{\prime} 18.1^{\prime \prime} \mathrm{N} 120^{\circ} 28^{\prime} 15.7^{\prime \prime} \mathrm{E}\right)$ in Chiayi City, Taiwan (R.O.C.). The leaves were obtained from more than three plants with a tree age of about 30 years. The leaves were oval, acute at base, obtuse at apex, with serrated edges and a dark green surface. The old leaves (orange or bright red) and young leaves (pale red) were not used, and only the dark green leaves were selected as the test material.

The Folin-Ciocalteu's reagent, gallic acid, rutin, ferrous sulfate heptahydrate, and myricitrin were used as the standards in the analysis and purchased from Sigma-Aldrich (St. Louis, MO, USA). Other chemical reagents purchased were acetonitrile from Merck (Darmstadt, Germany), $n$-hexane from BIONOVAS biotechnology (Toronto, CA, USA), ferric chloride, aluminium chloride, sodium carbonate, and methanol from Sigma-Aldrich (St. Louis, MO, USA), and 95\% ethanol from Genestar (Taiwan).

\subsection{Preparation of Leaves Powder}

The selected leaves were rinsed with deionized water several times to thoroughly remove dust and adhered objects from the surface of leaves. After that, leaves were freeze-dried to remove water and crushed to small pieces by conditioning. Then, they were ground to fine particles that were screened with 60 -mesh sieves to obtain powder. Finally, they were stored at $4{ }^{\circ} \mathrm{C}$ for use. The proximate composition of the leaves' powder was analyzed for water [17], ash [18], crude protein [19], and crude fat [20]. The results were $49.81 \pm 0.71 \%$ of water $(n=4), 2.57 \pm 0.06 \%$ of ash $(n=4), 1.21 \pm 0.07 \%$ of crude fat $(n=3)$, and $7.80 \pm 0.16 \%$ of crude protein $(n=8)$.

For the solvent extraction of bioactive compounds from the leaves, the efficiency is not only influenced by the physical properties and solubility of the components in the solvent, as well as the interaction between compounds but also affected by the ease of contacting the material with the solvent. It is favorable to the extraction efficiency when the processes facilitated the diffusion and affinity of bioactive compounds in the solvent within the matrix of the leaves. Prior to the extraction operation, the leaves' powder was first pretreated with $n$-hexane at room temperature for $1 \mathrm{~h}$ to reduce the resistance of solvent transporting through the waxy surface into the matrix of the solid particles. Then, 
$n$-hexane was separated via filtration and dried to get the defatted leaves (denoted as DL), which were used as raw material to extract the bioactive compounds.

\subsection{Extraction of Bioactive Compounds by Using UAE and SAE}

The UAE of the DL was performed using the bath system equipped with the frequency/electric power at $40 \mathrm{kHz} / 300 \mathrm{~W}$ or $120 \mathrm{kHz} / 300 \mathrm{~W}$ (LEO-3002S, LEO-3002H, LEO Ultrasonic Co., Taiwan), and the power density of the system was $0.028 \mathrm{~W} / \mathrm{mL}$.

With the setting of solvent to solid ratio, one gram of the DL was added into the solvent in a round-bottomed flask. Methanol, water, and different concentrations of aqueous ethanol solution $(95 \%$, $75 \%$, and $50 \%$ ethanol) were tested as the extraction solvent. The UAE was operated with ultrasound $(40 \mathrm{kHz} / 300 \mathrm{~W}$ or $120 \mathrm{kHz} / 300 \mathrm{~W})$ at $30^{\circ} \mathrm{C}$ for different times $(30,60,120,180,240$, and $300 \mathrm{~min})$. The SAE using $120 \mathrm{rpm}$ of shaking without ultrasound was carried out for comparison.

After completing the extraction operation at the sampling time, the solid-liquid mixture was centrifuged at $4000 \mathrm{rpm}$ for $10 \mathrm{~min}$ to obtain the supernatant containing the leaf extract. The solvent was removed from the supernatant under a vacuum to obtain the extract concentrate, which was subsequently purified by freeze-drying and storing in an opaque bottle at $4{ }^{\circ} \mathrm{C}$ for analysis. The yield of extract based on DL was estimated using Equation (1),

$$
\text { Yield of extract }(\%)=\frac{\text { Weight of dried extract }(\mathrm{g})}{\text { Weight of DL }(\mathrm{g})} \times 100 \%
$$

\subsection{Determination of Total Phenolic Content}

The total phenolic content (TPC) of the extract was determined according to the Folin-Ciocalteu method with a slight modification [21], and expressed as a gallic acid equivalent (GAE). To determine the TPC, the dried extract was re-dissolved in $75 \%$ aqueous ethanol to prepare the extract sample. Next, $500-\mu \mathrm{L}$ of the extract sample was mixed with $500 \mu \mathrm{L}$ of Folin-Ciocalteu reagent $(1 \mathrm{~N})$, and the mixture was set still for $5 \mathrm{~min}$. One milliliter of sodium carbonate solution (20\%) was added into the mixture and stored in a dark place for $8 \mathrm{~min}$. Then, the solution was centrifuged at 12,000 rpm for $10 \mathrm{~min}$ to get the supernatant for analysis. The absorbance of the supernatant at $730 \mathrm{~nm}$ was measured using a spectrophotometer (Hitachi, double-beam spectrophotometer UH5300, Tokyo, Japan) to determine the TPC from the calibration curve. The TPC was expressed as mg-GAE/g-DL by multiplying mg-GAE/mg-extract with mg-extract/g-DL.

\subsection{Determination of Total Flavonoid Content}

The total flavonoid content (TFC) of the extract was measured using the rutin equivalent (RE) according to the method of Khemakhem et al. (2017) with some modifications [22]. The extract sample was prepared as described above. Next, $250-\mu \mathrm{L}$ of the extract sample was mixed with $150 \mu \mathrm{L}$ of $5 \%$ sodium nitrite and $1 \mathrm{~mL}$ of de-ionized water in a $15-\mathrm{mL}$ test tube, and the mixture was set still at room temperature for $5 \mathrm{~min}$. Then, $75 \mu \mathrm{L}$ of aluminum chloride $(10 \%)$ and $1 \mathrm{~mL}$ of sodium hydroxide $(1 \mathrm{M})$ were, in succession, added into the mixture. Finally, the distilled water was introduced into the mixture to make up a total volume of $2.5 \mathrm{~mL}$ for analysis. The absorbance of the mixture at $510 \mathrm{~nm}$ was measured using a spectrophotometer to determine TFC and the TFC was expressed as mg-RE/g-DL by multiplying mg-RE/mg-extract with mg-extract/g-DL.

\subsection{HPLC Analysis of Myricitrin}

Following the method of Ahmad-Qasem et al. (2013) with a slight modification [23], the content of myricitrin in the extract sample was determined with a myricitrin standard (Sigma-Aldrich, USA) using a high performance liquid chromatography (HPLC) system, which was equipped with the diode array-detector set at $350 \mathrm{~nm}$ (SpectraSYSTEM UV1000, Thermo Fisher Scientific, San Jose, CA, USA), and a Mightysil RP-18 GP column $(5 \mu \mathrm{m}, 250 \mathrm{~mm} \times 4.6 \mathrm{~mm}$, Kanto Chemical Co., Tokyo, Japan). 
The mobile phase at $1 \mathrm{~mL} / \mathrm{min}$ of flow rate was composed of solvent $\mathrm{A}(0.1 \%$ trifluoroacetic acid $)$ and solvent B (acetonitrile), and the gradient was set as the following: for solvent B, 10 to $20 \%$ at 0 to $10 \mathrm{~min}$, 20 to $40 \%$ at 10 to $35 \mathrm{~min}, 40$ to $100 \%$ at 35 to $40 \mathrm{~min}, 100 \%$ maintained at 40 to $45 \mathrm{~min}$, and finally 100 to $10 \%$ at 45 to $46 \mathrm{~min}$. The content of myricitrin in the DL was expressed as $\mathrm{mg} / \mathrm{g}$-DL by multiplying $\mathrm{mg} / \mathrm{mg}$-extract with mg-extract/g-DL.

\subsection{Determination of Ferric Reducing Antioxidant Power}

Following the method of Shirzad et al. (2017) [24], the reagent for the analysis of ferric reducing antioxidant power (FRAP) was prepared and kept at $37^{\circ} \mathrm{C}$ for use. The FRAP reagent $(285 \mu \mathrm{L})$ was mixed with $15 \mu \mathrm{L}$ of the extract sample in a test tube. Next, $500-\mu \mathrm{L}$ of deionized water was added into the mixture and maintained at $4{ }^{\circ} \mathrm{C}$ for $4 \mathrm{~min}$. The absorbance of the sample at $593 \mathrm{~nm}$ was measured with a spectrophotometer using ferrous sulfate heptahydrate equivalent (FSE) for the determination of FRAP, which was expressed as mg-FSE/g-DL by multiplying mg-FSE/mg-extract with mg-extract/g-DL.

\subsection{Statistical Analysis}

Each experiment was performed in triplicate with three independent samples and the experimental data were expressed as mean \pm standard deviation. Statistical analysis was evaluated using a one-way ANOVA with Duncan's multiple range test using IBM SPSS Statistics 20 (IBM SPSS Statistics for Windows, Version 20.0, IBM Corp, Armonk, NY, USA). The significant difference was determined at $p<0.05$.

\section{Results and Discussion}

\subsection{Comparison of Bioactive Compounds and Myricitrin between UAE and SAE for Various Solvents}

The comparison of total phenolic compounds, flavonoids, and myricitrin from Elaeocarpus serratus L. was explored for various polarities of solvent (95\% ethanol, water, and methanol) between using UAE at $40 \mathrm{kHz} / 300 \mathrm{~W}$ of ultrasound (UAE-40), UAE at $120 \mathrm{kHz} / 300 \mathrm{~W}$ of ultrasound (UAE-120), and SAE at $120 \mathrm{rpm}$ of shaking (SAE-120) in the conditions of DL/solvent $=1 / 10(\mathrm{~g} / \mathrm{mL}), 30{ }^{\circ} \mathrm{C}$ of temperature, and $4 \mathrm{~h}$ of duration. The yield of extract, TPC, TFC, and myricitrin using $95 \%$ ethanol, water, and methanol are shown in Figure $1 \mathrm{a}-\mathrm{c}$ respectively.

As shown in Figure 1a, using 95\% ethanol as the solvent, the yield of extract, TPC, TFC, and myricitrin of UAE-40 were higher than that by SAE-120 and UAE-120. The TPC with UAE-40 (92.35 mg-GAE/g-DL) was 1.53 folds of that using SAE-120 (60.30 mg-GAE/g-DL). Similarly, the TFC of UAE-40 (53.14 mg-RE/g-DL) was 1.44 folds of that with SAE-120 (36.91 mg-RE/g-DL). Moreover, the content of myricitrin of UAE-40 was $4.41 \mathrm{mg} / \mathrm{g}-\mathrm{DL}$, which was 1.4 folds of that using SAE-120 (3.15 mg/g-DL) and 1.49 folds of that using UAE-120 (2.95 mg/g-DL). Further, using 95\% ethanol, the extraction efficiencies of yield of extract, TFC, and myricitrin were similar for SAE-120 and UAE-120 with insignificant differences, showing similar impact on the internal structure of leaves between UAE-120 and SAE-120, demonstrating that the cavitation effect by $120 \mathrm{kHz}$ of ultrasound and with the hydraulic effect by $120 \mathrm{rpm}$ of shaking displayed the similar impact on the changing of internal structure of leaves to make similar extraction efficiency of bioactive compounds from the leaves.

When using water as the solvent, the largest yield of extract, TPC, TFC, and content of myricitrin were obtained using UAE-40, all with significant differences to that using UAE-120 and SAE-120, as shown in Figure $1 \mathrm{~b}$. It was observed that the extraction efficiency of bioactive compounds was more effectively enhanced with UAE-40 than UAE-120 and SAE-120, due to the more intensified cavitation effect generated by $40 \mathrm{kHz}$ of ultrasound, so as to increase the affinity of bioactive compounds in the solvent. As shown in Figure 1c, when using methanol as the solvent, the highest extraction efficiency was obtained with UAE-40 among the tested extraction modes. The TPC, TFC, and myricitrin with UAE-40 were $74.77 \mathrm{mg}-\mathrm{GAE} / \mathrm{g}-\mathrm{DL}, 47.30 \mathrm{mg}-\mathrm{RE} / \mathrm{g}-\mathrm{DL}$, and $4.41 \mathrm{mg} / \mathrm{g}-\mathrm{DL}$, respectively, which were in order by $1.45,1.45$, and 1.38 folds of that using SAE-120. Moreover, the content of myricitrin via 
UAE-40 was 1.30 folds of that using UAE-120 (3.38 mg/g-DL). This showed that UAE-40 was more preferable than UAE-120 and SAE-120 in extracting bioactive compounds using methanol.

In addition, for a solvent effect using UAE-40, the largest TPC, TFC, and myricitrin were obtained with $95 \%$ ethanol, while methanol had almost equivalent efficiency on the extraction of flavonoids and myricitrin, but with a lower extractive capability on phenolic compounds than $95 \%$ ethanol. This showed that the extraction efficiency is not only dependent on the properties of the solvent (e.g., polarity, viscosity) and bioactive compounds (e.g., hydrophilicity, solubility, diffusivity) but also on the interaction of the plant material and solvent under specific extraction mode.

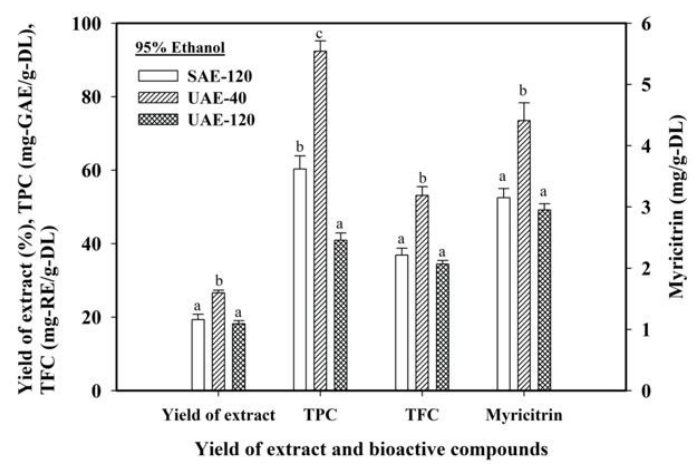

(a)

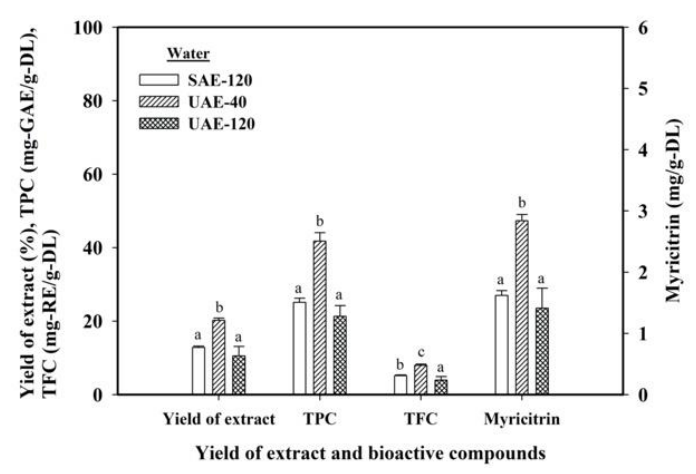

(b)

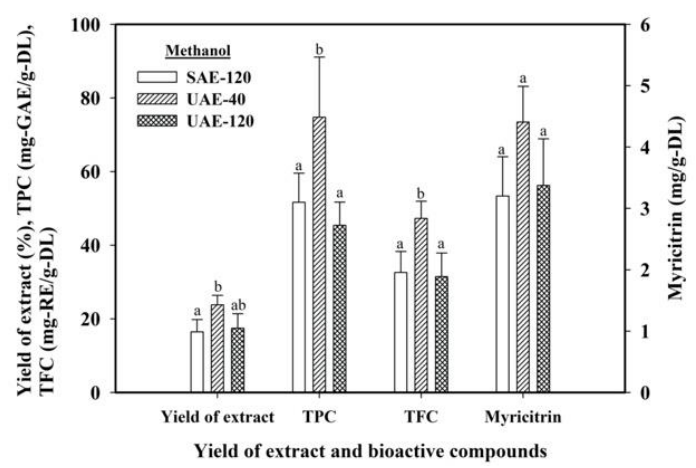

(c)

Figure 1. Comparison of the yield of extract, total phenolic content (TPC), total flavonoid content (TFC), and myricitrin between UAE-40, UAE-120, and SAE-120 with (a) 95\% ethanol, (b) water, and (c) methanol as the solvent. Conditions: DL/solvent $=1 / 10(\mathrm{~g} / \mathrm{mL}), 30^{\circ} \mathrm{C}, 4 \mathrm{~h}$. Data were expressed as mean \pm standard deviations from triplicate experiments. Different superscript letters at the same group were significantly different $(p<0.05)$ using the Duncan's multiple range test. Abbreviations: defatted leaves (DL), gallic acid equivalent (GAE), and rutin equivalent (RE). 


\subsection{Effect of Concentration of Aqueous Ethanol on the Extraction Efficiency by UAE}

The hydrophilic property of the compounds existing in the plant materials varied significantly, such that the compounds extracted from the plant materials and antioxidant activity of the extract were dependent on the polarity and viscosity of the solvent and the interaction of the solutes in the solvent. Table 1 shows the effect of concentration of aqueous ethanol (95\% ethanol, $75 \%$ ethanol, and $50 \%$ ethanol) on the extraction of bioactive compounds and antioxidant activity using UAE.

Table 1. Effects of \% aqueous ethanol on yield of extract, TPC, TFC, myricitrin, and ferric reducing antioxidant power (FRAP) by UAE-40.

\begin{tabular}{cccccc}
\hline \% of Ethanol & $\begin{array}{c}\text { Yield of } \\
\text { Extract (\%) }\end{array}$ & $\begin{array}{c}\text { TPC } \\
\text { (mg-GAE/g-DL) }\end{array}$ & $\begin{array}{c}\text { TFC } \\
\text { (mg-RE/g-DL) }\end{array}$ & $\begin{array}{c}\text { Myricitrin } \\
\text { (mg/g-DL) }\end{array}$ & $\begin{array}{c}\text { FRAP } \\
\text { (mg-FSE/g-DL) }\end{array}$ \\
\hline $95 \%$ & $26.63 \pm 0.70^{\mathrm{a}}$ & $92.35 \pm 2.85^{\mathrm{b}}$ & $53.14 \pm 2.40^{\mathrm{b}}$ & $4.41 \pm 0.29^{\mathrm{b}}$ & $199.75 \pm 3.01^{\mathrm{b}}$ \\
$75 \%$ & $18.35 \pm 0.93^{\mathrm{a}}$ & $40.91 \pm 3.80^{\mathrm{a}}$ & $23.03 \pm 1.48^{\mathrm{a}}$ & $2.97 \pm 0.27^{\mathrm{a}}$ & $86.51 \pm 1.68^{\mathrm{a}}$ \\
$50 \%$ & $18.92 \pm 6.95^{\mathrm{a}}$ & $38.71 \pm 12.59^{\mathrm{a}}$ & $17.99 \pm 6.67^{\mathrm{a}}$ & $2.44 \pm 0.81^{\mathrm{a}}$ & $79.08 \pm 26.87^{\mathrm{a}}$ \\
\hline
\end{tabular}

Conditions: DL/solvent $=1 / 10(\mathrm{~g} / \mathrm{mL}), 30^{\circ} \mathrm{C}, 40 \mathrm{kHz} / 300 \mathrm{~W}, 4 \mathrm{~h}$. Data were expressed as mean \pm standard deviation from triplicate experiments. Different superscript letters $\left({ }^{\mathrm{a}}\right.$ and $\left.{ }^{\mathrm{b}}\right)$ at the same column were significantly different $(p<0.05)$ using the Duncan's multiple range test.

The polarity of the aqueous ethanol increased with the decrease of ethanol concentration [25]. At conditions of $1 / 10(\mathrm{~g} / \mathrm{mL})$ of DL to solvent ratio, $30^{\circ} \mathrm{C}$ and $4 \mathrm{~h}$ of duration, the largest TPC, TFC, and myricitrin content were obtained using $95 \%$ ethanol as the solvent. All the orders of TPC, TFC, myricitrin, and FRAP for different concentrations of aqueous ethanol were $95 \%>75 \%>$ or $\approx 50 \%$ ethanol. However, $75 \%$ ethanol showed slightly higher mean extraction efficiencies of TPC, TFC, myricitrin, and FRAP than 50\% ethanol, but with insignificant differences. These results revealed that the phenolic compounds and flavonoids existing in the Elaeocarpus serratus L. leaves were largely more hydrophobic, so as to make the hydrophobic phenolic compounds and flavonoids much more extracted with higher concentration of aqueous ethanol.

\subsection{Comparison of Antioxidant Capacity of Extract between UAE and SAE}

Phenolic compounds are the secondary metabolites of plants and exhibit biological effects to defend against free radicals. As described above, Elaeocarpus serratus L. leaves are rich in phenolic compounds and have significant antioxidant activity. However, the extraction processes using various solvents and extraction modes would result in different profiles and amounts of bioactive compounds, thus possibly leading to the antioxidant capacity of the extracts varied between each mode. The comparisons of FRAP antioxidant capacity using UAE-40, UAE-120, and SAE-120 with different solvents are displayed in Table 2.

Table 2. Comparison of SAE and UAE for FRAP using 95\% ethanol, water, and methanol.

\begin{tabular}{cccc}
\hline \multirow{2}{*}{ Extraction Mode } & \multicolumn{3}{c}{ FRAP (mg-FSE/g-DL) } \\
\cline { 2 - 4 } & $\mathbf{9 5 \%}$ Ethanol & Water & Methanol \\
\hline SAE-120 & $204.48 \pm 15.59^{\mathrm{b}}$ & $43.43 \pm 5.17^{\mathrm{b}}$ & $132.13 \pm 20.88^{\mathrm{a}}$ \\
UAE-40 & $199.75 \pm 3.01^{\mathrm{b}}$ & $30.45 \pm 1.15^{\mathrm{a}}$ & $184.09 \pm 28.47^{\mathrm{a}}$ \\
UAE-120 & $174.48 \pm 10.91^{\mathrm{a}}$ & $28.25 \pm 4.87^{\mathrm{a}}$ & $140.61 \pm 30.78^{\mathrm{a}}$ \\
\hline
\end{tabular}

Conditions: DL/solvent $=1 / 10(\mathrm{~g} / \mathrm{mL}), 30^{\circ} \mathrm{C}, 4 \mathrm{~h}$. Data were expressed as mean \pm standard deviation from triplicate experiments. Different superscript letters $\left({ }^{\mathrm{a}}\right.$ and $\left.{ }^{\mathrm{b}}\right)$ at the same column were significantly different $(p<0.05)$ using the Duncan's multiple range test.

As shown in Table 2, for 95\% ethanol, the FRAP values were insignificantly different for UAE-40 (199.75 mg-FSE/g-DL) and SAE-120 (204.48 mg-FSE/g-DL), but both were larger than that for UAE-120 (174.48 mg-FSE/g-DL). By using methanol as the solvent, the largest FRAP value occurred 
in UAE-40 (184.09 mg-FSE/g-DL), but with insignificant differences to that of SAE-120 and UAE-120. While for water, the FRAP by SAE-120 was a little higher than that by UAE-40 and UAE-120, but the differences were not much. This might be because the chemical profile extracted with water by UAE was substantially different from SAE, including the interaction and synergism effect between the antioxidants in the mixture [26].

It was found that the profile of antioxidants that could be extracted significantly depended on the specific solvent employed. Either for SAE-120 or for UAE-40 and UAE-120, the order of FRAP value was $95 \%$ ethanol $>$ methanol $>$ water. This demonstrated that the polyphenols and flavonoids existing in Elaeocarpus serratus L. leaves were dominated in hydrophobic behavior. From the overall results on the yield of extract, TPC, TFC, myricitrin, and FRAP, the combination of UAE at $40 \mathrm{kHz} / 300 \mathrm{~W}$ and 95\% ethanol showed the production of preferable extract from Elaeocarpus serratus L. leaves for further potential application in foods.

\subsection{Kinetic Modelling for Extraction of Myricitrin and Effect of Extraction Time on TPC and TFC}

In the solid-liquid extraction of substances from the plant materials, the factors influencing the extraction rate and affinity of the target compounds in the solvent were complex, including swelling of the solid material in the solvent, diffusion of the solvent into the interior of the solid material, dissolution of the compounds into the solvent in the solid-liquid interface, transport of the compounds to the outer surface of the solid particle, and the mass-transfer of the compounds to the bulk liquid [12]. In the present system, an extraction model that combines such complex factors as an overall effect would be useful in evaluating the extraction efficiency in different conditions. Hence, the first-order kinetic model using the observed extraction rate coefficient was applied to describe the extraction kinetics of myricitrin in the solvent. The rate of change of myricitrin in the solvent is as follows:

$$
\frac{d C_{m}}{d t}=k_{m, o b s}\left(C_{m \infty}-C_{m}\right)
$$

where $C_{m}(\mathrm{mg} / \mathrm{mL})$ is the concentration of myricitrin extracted into the solvent at the time $t(\mathrm{~min})$, $C_{m \infty}(\mathrm{mg} / \mathrm{mL})$ is the limiting concentration of myricitrin in the solvent as $t$ approaching infinity, and $k_{m, o b s}\left(\mathrm{~min}^{-1}\right)$ is the observed extraction rate coefficient for myricitrin. Using the initial condition $C_{m}=$ 0 at $t=0$, Equation (2) is solved to give:

$$
C_{m}=C_{m \infty}\left(1-\exp \left(-k_{m, o b s} t\right)\right)
$$

The observed extraction rate coefficient $k_{m, o b s}$ and the limiting concentration $C_{m \infty}$ can be correlated by the nonlinear least-square method using Equation (3).

The results for kinetic modelling of extraction of myricitrin with $95 \%$ ethanol and water are shown in Figure 2, in which the experimental conditions were $1 / 10(\mathrm{~g} / \mathrm{mL})$ of $\mathrm{DL}$ to solvent ratio and $30^{\circ} \mathrm{C}$ with UAE at $40 \mathrm{kHz} / 300 \mathrm{~W}$. The concentration of myricitrin was estimated from myricitrin with the DL to solvent ratio. It was observed that, in $30 \mathrm{~min}$, the yields of extract were $26.38 \pm 0.66 \%$ and 18.08 $\pm 0.33 \%$ by $95 \%$ ethanol and water, respectively, and the corresponding contents of myricitrin in the extract were $3.49 \pm 0.06 \mathrm{mg} / \mathrm{g}$-DL for $95 \%$ ethanol and $2.54 \pm 0.06 \mathrm{mg} / \mathrm{g}$-DL for water, with which the concentrations of myricitrin were estimated as $0.349 \mathrm{mg} / \mathrm{mL}$ in $95 \%$ ethanol and $0.254 \mathrm{mg} / \mathrm{mL}$ in water. Obviously, using $95 \%$ ethanol was able to dissolve more myricitrin when using water, showing that, in this multicomponent extraction system, the solvent $95 \%$ ethanol had a larger capability to solubilize myricitrin from the internal structure of the leaves than water had. Thus, limiting concentration of myricitrin in the solvent could be evaluated. 


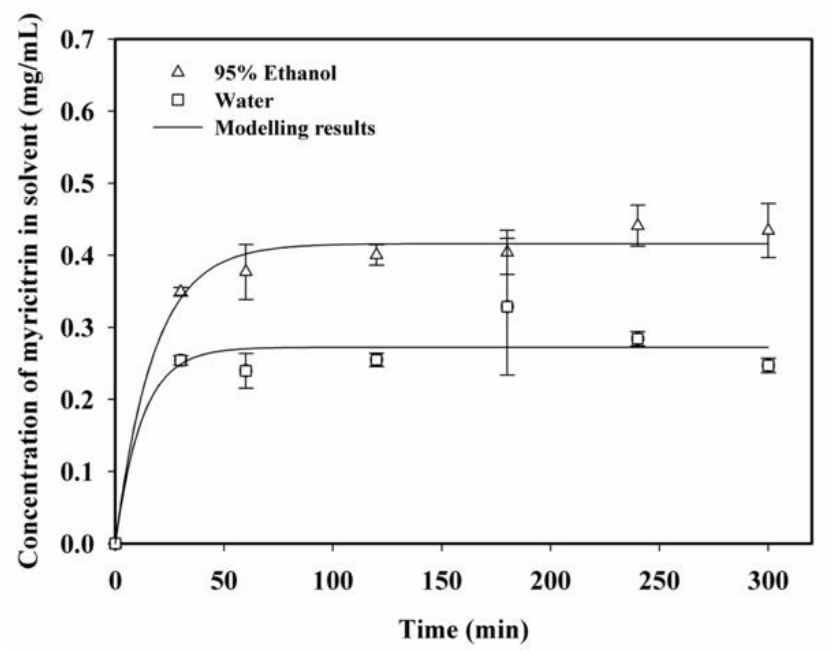

Figure 2. Variation of the myricitrin concentration against the extraction time by using $95 \%$ ethanol or water as the solvent. Conditions: DL/solvent $=1 / 10(\mathrm{~g} / \mathrm{mL}), \mathrm{UAE}$ at $40 \mathrm{kHz} / 300 \mathrm{~W}$ of ultrasound, $30{ }^{\circ} \mathrm{C}$. Data were expressed as mean \pm standard deviations from triplicate experiments. Symbols: experimental data; lines: modelling results.

As shown in Figure 2, when the extraction time was longer than $120 \mathrm{~min}$, the concentration of myricitrin gradually approached to the limiting concentration. A similar trend was also observed by Nayak et al. (2018) [27]. The kinetic parameters of extraction of myricitrin in $95 \%$ ethanol and water were correlated by using Equation (3), and the results are shown in Table 3.

Table 3. Correlated values of $k_{m, o b s}$ and $C_{m \infty}$ of myricitrin in the solvent.

\begin{tabular}{cccc}
\hline Solvent & $\begin{array}{c}\boldsymbol{k}_{\boldsymbol{m}, \boldsymbol{o b s}} \\
\left(\mathbf{m i n}^{-\mathbf{1}}\right)\end{array}$ & $\begin{array}{c}\boldsymbol{C}_{\boldsymbol{m} \infty} \\
(\mathbf{m g} / \mathbf{m L})\end{array}$ & R-Square \\
\hline 95\% Ethanol & 0.0566 & 0.416 & 0.9857 \\
Water & 0.0818 & 0.272 & 0.9221 \\
\hline
\end{tabular}

The kinetic parameters were correlated from experimental data by using Equation (3). Conditions: DL/solvent = $1 / 10(\mathrm{~g} / \mathrm{mL}), 30^{\circ} \mathrm{C}, 40 \mathrm{kHz} / 300 \mathrm{~W}$.

As displayed in Table 3, the observed extraction rate coefficient using water $\left(0.0818 \mathrm{~min}^{-1}\right)$ was higher than that using $95 \%$ ethanol $\left(0.0566 \mathrm{~min}^{-1}\right)$. This was due to myricitrin having more hydrophilic properties, so that the initial affinity of myricitrin in water was larger than that in $95 \%$ ethanol. While the $C_{m \infty}$ of myricitrin was larger in $95 \%$ ethanol $(0.416 \mathrm{mg} / \mathrm{mL})$ than in water, showing that the cavitation effect of ultrasound $(40 \mathrm{kHz} / 300 \mathrm{~W})$ was more severe in $95 \%$ ethanol than in water to promote the dissolution of myricitrin, leading to much enhancement of myricitrin extracted in $95 \%$ ethanol solvent.

Besides, in order to verify the extraction limits of the total phenolic compounds and total flavonoids by $95 \%$ ethanol and water, the variations of TPC and TFC against the extraction time of UAE- 40 were evaluated. The results are displayed in Figure $3 a, b$ for TPC and TFC, respectively.

As shown in Figure 3, the trends for the variations of TPC and TFC against time were all similar to the myricitrin concentration of $95 \%$ ethanol and water. The contents of total phenolic compounds and flavonoids obtained were gradually approached to their extraction limits under ultrasound $(40 \mathrm{kHz} / 300 \mathrm{~W})$ when the extraction time was longer than $120 \mathrm{~min}$, showing that UAE-40 exhibited high efficiency in the extraction of Elaeocarpus serratus L. leaves. 


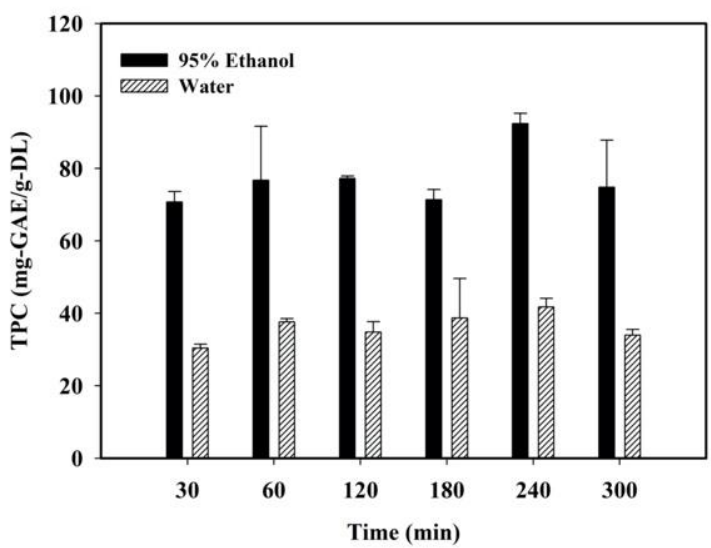

(a)

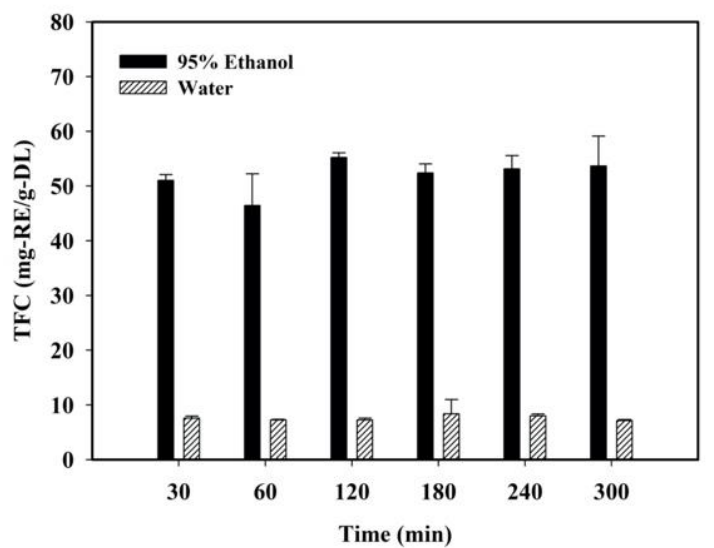

(b)

Figure 3. Variation of (a) TPC and (b) TFC against the extraction time by using $95 \%$ ethanol or water as the solvent. Conditions: DL/solvent $=1 / 10(\mathrm{~g} / \mathrm{mL}), \mathrm{UAE}$ at $40 \mathrm{kHz} / 300 \mathrm{~W}$ of ultrasound, $30{ }^{\circ} \mathrm{C}$. Data were expressed as mean \pm standard deviations from triplicate experiments.

\section{Conclusions}

In this study, the valorization of Elaeocarpus serratus L. leaves was explored using ultrasound to assist in the extraction of total phenolic compounds, total flavonoids, and myricitrin. Using $40 \mathrm{kHz}$ of ultrasound and $95 \%$ ethanol, the high contents of bioactive compounds and myricitrin from the leaves was achieved, and the high antioxidant activity of the extract was observed for UAE at $40 \mathrm{kHz}$. In addition, the kinetic model for the solid-liquid extraction was proposed and successfully applied to correlate the observed extraction rate coefficient and limiting concentration of myricitrin in the multicomponent system. In summary, the extract of Elaeocarpus serratus L. leaves can serve as an economical source of myricitrin and bioactive compounds via the UAE process. This study proposes an effective and sustainable method to provide bioactive extracts that can potentially be applied in foods for human health benefits.

Author Contributions: Conceptualization, C.-Y.Y.; methodology, C.-Y.Y.; investigation, Y.-H.C.; data curation, Y.-H.C.; formal analysis, Y.-H.C. and C.-Y.Y.; writing-original draft preparation, C.-Y.Y.; writing-review and editing, C.-Y.Y.; project administration, C.-Y.Y.; funding acquisition, C.-Y.Y. All authors have read and agreed to the published version of the manuscript.

Funding: This research was funded by Ministry of Science and Technology, Taiwan (R.O.C.), project No. MOST 107-2221-E-030-006-MY2.

Acknowledgments: The authors thank the Ministry of Science and Technology, Taiwan (R.O.C.) for providing the financial support for this research (project No. MOST 107-2221-E-030-006-MY2).

Conflicts of Interest: The authors declare no conflict of interest.

\section{References}

1. Geetha, D.H.; Jayashree, I.; Rajeswari, M. GC-MS analysis of ethanolic extract of Elaeocarpus Serratus L. Eur. J. Pharm. Med. Res. 2015, 2, 296-302.

2. Raji, R.; Siril, E.A. Cloning of Ceylon olive (Elaeocarpus serratus L.) using conventional methods. J. Hortic. Sci. Biotechnol. 2016, 91, 292-298. [CrossRef]

3. Yang, C.F. Manual of Fruit Trees in Taiwan; Chia-Yi Experiment Station, Taiwan Agricultural Research Institute: Chia-Yi, Taiwan, 1951; pp. 73-76.

4. Dadhich, A.; Rishi, A.; Sharma, G.; Chandra, S. Phytochemicals of Elaeocarpus with their therapeutic value: A review. Int. J. Pharm. Biol. Sci. 2013, 4, 591-598.

5. Geetha, D.H.; Rajeswari, M.; Jayashree, I. Chemical profiling of Elaeocarpus serratus L. by GC-MS. Asian Pac. J. Trop. Biomed. 2013, 3, 985-987. [CrossRef] 
6. Jayasinghe, L.; Amarasinghe, N.R.; Arundathie, B.S.; Rupasinghe, G.K.; Jayatilake, N.A.N.; Fujimoto, Y. Antioxidant flavonol glycosides from Elaeocarpus serratus and Filicium decipiens. Nat. Prod. Res. 2012, 26, 717-721. [CrossRef]

7. Domitrović, R.; Rashed, K.; Cvijanović, O.; Vladimir-Knežević, S.; Škoda, M.; Višnić, A. Myricitrin exhibits antioxidant, anti-inflammatory and antifibrotic activity in carbon tetrachloride-intoxicated mice. Chem. Biol. Interact. 2015, 230, 21-29. [CrossRef]

8. Hobbs, C.A.; Swartz, C.; Maronpot, R.; Davis, J.; Recio, L.; Koyanagi, M.; Hayashi, S.M. Genotoxicity evaluation of the flavonoid, myricitrin, and its aglycone, myricetin. Food Chem. Toxicol. 2015, 83, 283-292. [CrossRef]

9. Pereira, M.; Siba, I.P.; Chioca, L.R.; Correia, D.; Vital, M.A.; Pizzolatti, M.G.; Santos, A.R.; Andreatini, R. Myricitrin, a nitric oxide and protein kinase $\mathrm{C}$ inhibitor, exerts antipsychotic-like effects in animal models. Prog. Neuropsychopharmacol. Biol. Psychiatry 2011, 35, 1636-1644. [CrossRef]

10. Meyer, E.; Mori, M.A.; Campos, A.C.; Andreatini, R.; Guimaraes, F.S.; Milani, H.; de Oliveira, R.M. Myricitrin induces antidepressant-like effects and facilitates adult neurogenesis in mice. Behav. Brain Res. 2017, 316, 59-65. [CrossRef]

11. Vilkhu, K.; Mawson, R.; Simons, L.; Bates, D. Applications and opportunities for ultrasound assisted extraction in the food industry-A review. Innov. Food Sci. Emerg. Technol. 2008, 9, 161-169. [CrossRef]

12. Yu, C.A.; Yang, C.Y. Effect of ultrasound on the extraction of bioactive aglycone isoflavones for the green valorization of black soybean residue (okara). J. Food Process. Preserv. 2019, 43, e13944. [CrossRef]

13. Dobrinčić, A.; Repajić, M.; Garofulić, I.E.; Tuđen, L.; Dragović-Uzelac, V.; Levaj, B. Comparison of different extraction methods for the recovery of olive leaves polyphenols. Processes 2020, 8, 1008. [CrossRef]

14. Guo, X.; Shang, X.; Zhou, X.; Zhao, B.; Zhang, J. Ultrasound-assisted extraction of polysaccharides from Rhododendron aganniphum: Antioxidant activity and rheological properties. Ultrason. Sonochem. 2017, 38, 246-255. [CrossRef] [PubMed]

15. Chuyen, H.V.; Roach, P.D.; Golding, J.B.; Parks, S.E.; Nguyen, M.H. Ultrasound-assisted extraction of GAC Peel: An optimization of extraction conditions for recovering carotenoids and antioxidant capacity. Processes 2020, 8, 8. [CrossRef]

16. Ismail, B.B.; Guo, M.; Pu, Y.; Wang, W.; Ye, X.; Liu, D. Valorisation of baobab (Adansonia digitata) seeds by ultrasound assisted extraction of polyphenolics. Optimisation and comparison with conventional methods. Ultrason. Sonochem. 2019, 52, 257-267. [CrossRef]

17. Helrich, K. (Ed.) Moisture in Animal Feed, AOAC 920.36. In Official Methods of Analysis of AOAC International, 15th ed.; AOAC Inc.: Arlington, VA, USA, 1990.

18. Horwitz, W. (Ed.) Ash of animal feed, AOAC 942.05 (4.1.10). In Official Methods of Analysis of AOAC International, 17th ed.; AOAC International: Gaithersburg, MD, USA, 2000.

19. Bureau of Standards, Metrology and Inspection. Method of Test for Crude Protein in Food, CNS 5035 N6116; Bureau of Standards, Metrology and Inspection, Ministry of Economic Affairs, R.O.C.: Taipei, Taiwan, 1986.

20. Bureau of Standards, Metrology and Inspection. Methods of Test for Crude Fat in Food, CNS 5036 N6117; Bureau of Standards, Metrology and Inspection, Ministry of Economic Affairs, R.O.C.: Taipei, Taiwan, 1984.

21. Kujala, T.S.; Loponen, J.M.; Klika, K.D.; Pihlaja, K. Phenolics and betacyanins in red beetroot (Beta vulgaris) root: Distribution and effect of cold storage on the content of total phenolics and three individual compounds. J. Agric. Food Chem. 2000, 48, 5338-5342. [CrossRef]

22. Khemakhem, I.; Gargouri, O.D.; Dhouib, A.; Ayadi, M.A.; Bouaziz, M. Oleuropein rich extract from olive leaves by combining microfiltration, ultrafiltration and nanofiltration. Sep. Purif. Technol. 2017, 172, 310-317. [CrossRef]

23. Ahmad-Qasem, M.H.; Cánovas, J.; Barrajon-Catalan, E.; Micol, V.; Cárcel, J.A.; García-Pérez, J.V. Kinetic and compositional study of phenolic extraction from olive leaves (var. Serrana) by using power ultrasound. Innov. Food Sci. Emerg. Technol. 2013, 17, 120-129. [CrossRef]

24. Shirzad, H.; Niknam, V.; Taheri, M.; Ebrahimzadeh, H. Ultrasound-assisted extraction process of phenolic antioxidants from olive leaves: A nutraceutical study using RSM and LC-ESI-DAD-MS. J. Food Sci. Technol. 2017, 54, 2361-2371. [CrossRef]

25. Mohsen-Nia, M.; Amiri, H. Measurement and modelling of static dielectric constants of aqueous solutions of methanol, ethanol and acetic acid at $\mathrm{T}=293.15 \mathrm{~K}$ and $91.3 \mathrm{kPa}$. J. Chem. Thermodyn. 2013, 57, 67-70. [CrossRef] 
26. Piluzza, G.; Bullitta, S. Correlations between phenolic content and antioxidant properties in twenty-four plant species of traditional ethnoveterinary use in the Mediterranean area. Pharm. Biol. 2011, 49, 240-247. [CrossRef] [PubMed]

27. Nayak, A.; Bhushan, B.; Rosales, A.; Turienzo, L.R.; Cortina, J.L. Valorisation potential of Cabernet grape pomace for the recovery of polyphenols: Process intensification, optimisation and study of kinetics. Food Bioprod. Process. 2018, 109, 74-85. [CrossRef] 